\title{
UMA VISÃO DA QUÍMICA BIOINORGÂNICA MEDICINAL
}

\author{
Anna Maria Canavarro Benite* \\ Instituto de Química, Universidade Federal de Goiás, Campus II - Samambaia, CP 131, 74000-970 Goiânia - GO, Brasil \\ Sérgio de Paula Machado \\ Departamento de Química Inorgânica, Instituto de Química, Universidade Federal do Rio de Janeiro, CT, Ilha do Fundão, \\ Cidade Universitária, 21945-970 Rio de Janeiro - RJ, Brasil \\ Eliezer J. Barreiro \\ Faculdade de Farmácia, Universidade Federal do Rio de Janeiro, CCS, Ilha do Fundão, Cidade Universitária, $21944-910$ Rio de \\ Janeiro - RJ, Brasil \\ Recebido em 2/2/07; aceito em 18/5/07; publicado na web em 9/11/07
}

\begin{abstract}
MEDICINAL BIOINORGANIC CHEMISTRY. Metals play a vital role in human and plant physiology and important research is directed towards exploring the interrelated mechanisms that govern their interactions with biomolecules. Bioinorganic medicinal chemistry studies the functions, processing, storage and applications of metal ions and their complexes in biological systems. This paper presents a brief discussion about on interactions of metals with biomolecules that determine their intracellular accumulation, where metal ions may fulfill essential functions in cellular metabolism or, in certain cases, exert toxic effects towards cells.
\end{abstract}

Keywords: metals; coordination chemistry.

\section{INTRODUÇÃO}

Uma característica dos metais que os torna tão importantes como componentes (funcionais e estruturais) dos seres vivos é sua propensão em perder elétrons facilmente formando íons com cargas positivas, que tendem a ser solúveis em fluidos biológicos. É na forma catiônica que os metais desempenham suas principais funções biológicas ${ }^{1-3}$.

Enquanto íons metálicos apresentam-se deficientes de elétrons, biomoléculas tais como proteínas e DNA são ricas em elétrons. A atração entre estas oposições de cargas conduz a uma tendência geral de "íons metálicos interagirem com moléculas biológicas". Os compostos de coordenação formados a partir destas interações são extremamente estáveis e podem ser definidos a partir das Equações 1-3 ${ }^{4-5}$.

$\mathrm{M}_{\mathrm{aq}}^{\mathrm{n}+}+\mathrm{L}_{\mathrm{aq}} \stackrel{K}{\longleftrightarrow} \mathrm{ML}_{\mathrm{aq}}^{\mathrm{n}+}$

$\mathrm{K}=\mathrm{e}^{-\Delta \mathrm{Goc} / \mathrm{RT}}$

$\Delta \mathrm{G}^{\mathrm{o}}{ }_{\mathrm{c}}=\Delta \mathrm{H}_{\mathrm{c}}^{\mathrm{o}}-\mathrm{T} \Delta \mathrm{S}_{\mathrm{c}}^{\mathrm{o}}$

A reação de complexação envolve a desolvatação do íon metálico e das biomoléculas, o processo de complexação e finalmente a solvatação do complexo formado. Efeitos eletrônicos (e.g. tipo de ligação entre a biomolécula e o íon metálico etc), efeitos estéricos, termos entrópicos e efeitos de solvatação constituem a base da estabilidade do complexo formado ${ }^{6}$.

A coordenação entre biomoléculas com íons metálicos inclui a deformação do centro metálico pela biomolécula e vice-versa. Associada a esta deformação está a perda de energia estérica que é compensada pela energia da ligação que resulta da formação da

*e-mail: anna@quimica.ufg,br

\# Laboratório de Química Inorgânica Computacional

\& Laboratório de Avaliação e Síntese de Substâncias Bioativas (LASSBio) ligação átomo doador de par de elétrons da biomolécula com o íon metálico (Equação 4).

$\Delta G_{c}^{o}=\left(\Delta H^{o}{ }_{M L}+\Delta U_{\text {tensão }}\right)-T \Delta S_{c}^{o}$

$\mathrm{Na}$ organização das estruturas biomolécula livre, metal e, finalmente, o complexo influenciam a especificidade do par íon metálico/biomolécula ligante que envolve tamanho e forma, assim como flexibilidade e liberdade torsional da biomolécula ${ }^{7,8}$.

Existem numerosos conceitos e teorias que são utilizados na interpretação e previsão da estabilidade dos complexos metalbiomoléculas e propriedades relacionadas (e.g. previsão dos potenciais redox ${ }^{9-11}$, a correlação entre potenciais redox e características eletrônicas das biomoléculas ${ }^{12-14}$ e/ou sinais de $\mathrm{RMN}^{15}$ ). Algumas destas teorias são puramente qualitativas, outras permitem previsões semiquantitativas, mas todas são limitadas em sua aplicabilidade. Entretanto, freqüentemente as interações metaisbiomoléculas são interpretadas, com sucesso, com base no princípio HSBA de Pearson (dureza e maciez de ácidos e bases) ${ }^{16}$.

A teoria dos ácidos e bases de Lewis serviu de base para uma descrição qualitativa da dureza e maciez dos ácidos e bases feita por Pearson ${ }^{17}$. De acordo com Pearson, uma espécie "macia" em geral tem grande raio atômico, baixa carga efetiva nuclear e alta polarizabilidade, enquanto que uma espécie "dura" possui características opostas. Enquanto os íons metálicos são considerados ácidos de Lewis, seus contra-íons são átomos ligantes com características de dureza e maciez. No contexto fisiopatológico, estes ligantes estão representados pelas cadeias protéicas, pelas bases dos ácidos nucléicos, pequenos constituintes do citoplasma celular, cofatores orgânicos e, claro, pela água. Embora possam existir algumas exceções, a regra geral enuncia que ácidos duros se ligam a bases duras enquanto ácidos macios preferem bases macias. Uma melhor visualização da distinção entre as espécies macias e duras pode ser observada na Figura 1, que representa a correlação entre potencial de ionização e a razão carga/raio de algumas espécies $\mathrm{M}^{2+}$. Este gráfico é uma maneira simplificada de representar a distinção 
entre íons metálicos duros e macios. Ele fornece qualitativamente a série de Irving-Williams ${ }^{18,19}$.

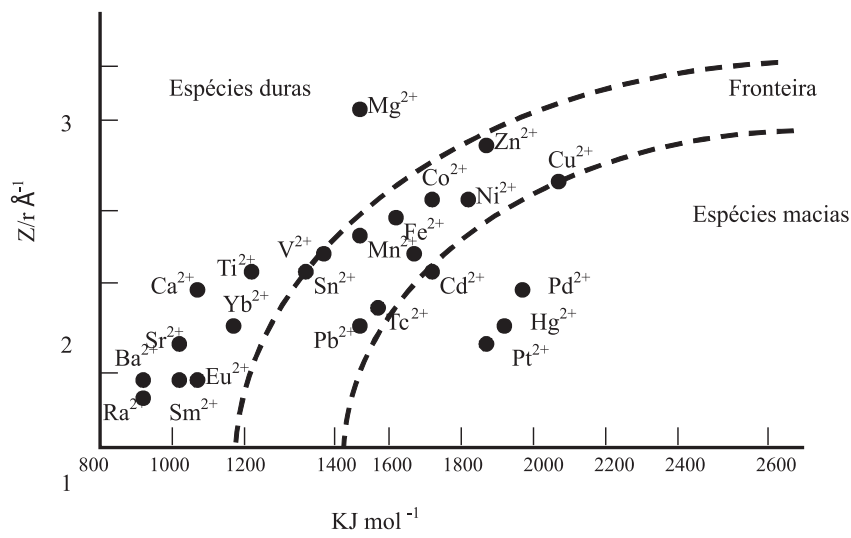

Figura 1. Relação entre potencial de ionização, aqui para $\mathrm{M}^{2+}$, e a razão carga/raio iônica. Representação gráfica da distinção entre íons metálicos duros e macios

A estabilidade termodinâmica do centro metálico em ambientes biológicos é determinada não somente por um estado de oxidação particular, pela biomolécula e geometria de coordenação, mas também pela estrutura tridimensional do complexo formado, pela estequiometria e disponibilidade das biomoléculas para coordenação. Outros fatores tais como hidrofilicidade ou hidrofobicidade local, impedimento espacial dos sítios de coordenação, e grupos ligantes de hidrogênio que podem interagir com átomos ligados e não ligados da esfera de coordenação metálica podem aumentar ou diminuir a estabilidade dos complexos de metalo-biomoléculas. A carga positiva dos íons metálicos estabiliza os ligantes próticos (ânions ácidos) da esfera de coordenação ${ }^{20}$.

\section{METAL-BIOMOLÉCULAS E A PERMEAÇÃO ATRAVÉS DA MEMBRANA CELULAR}

Um processo celular dinâmico reside na extração de íons metálicos minerais e inserção nas biomoléculas. Para muitos íons, tais como $\mathrm{Na}^{+}, \mathrm{Mg}^{2+}$, ou $\mathrm{Zn}^{2+}$, solubilidade não representa um problema e apenas concentrações milimolares são necessárias. Alguns elementos tais como ferro, entretanto, são tão insolúveis em pH fisiológico que estão indisponíveis. Solubilização à parte, íons metálicos devem ser absorvidos pelas células, um mecanismo que ainda permanece não muito claro e caracterizado. Dois são os possíveis caminhos ${ }^{21,22}$.

Íons positivos, tais como sódio, têm acesso ao meio intracelular, através de canais e bombas especiais na membrana celular ${ }^{21}$. Para outros íons, existem biomoléculas que facilitam seu transporte através da membrana celular, onde estes encontram proteínas transportadoras específicas (Tabela 1). Existem ainda vários outros mecanismos pelos quais a célula pode captar e concentrar um íon metálico específico em seu ambiente.

As espécies carregadas negativamente entram na célula por um sistema específico denominado transporte de ânions, tais como íon sulfato, por meio da membrana externa. Uma vez dentro da célula, o ânion é reduzido, liga-se a um componente intracelular e, então, é difundido para o meio. Um exemplo interessante é o cromo, que, na forma do ânion cromato, $\mathrm{CrO}_{4}^{2-}$, é carcinogênico. Seu mecanismo de entrada na célula pode ser ilustrado pela Figura 2.

O cromo é celularmente internalizado pelo sistema de transporte de ânions. No citoplasma, ele reage com a glutationa (GSH),
Tabela 1. Algumas proteínas que se ligam a íons metálicos através de ligações cruzadas e são capazes de carreá-los através das membranas celulares (interna e/ou externa)

\begin{tabular}{|c|c|c|}
\hline Helicoidais $^{\mathrm{a}}$ & $\alpha / \beta$ & Folha $\beta$ \\
\hline Mioglobinas & $\operatorname{Lisosima}(S-S)^{\mathbf{c}}$ & Azurina \\
\hline $\begin{array}{l}\text { Citocromo C } \\
(\mathrm{S}-\mathrm{C})^{\mathbf{b}}\end{array}$ & Fosforilase & $\begin{array}{l}\text { Neurotoxina } \\
(S-S)^{\mathbf{c}}\end{array}$ \\
\hline Hemeritrina & Carboxipeptidase $(\mathrm{S}-\mathrm{S})^{\mathbf{c}}$ & Prealbumina \\
\hline Parvalbumina & Fosfoglicerato kinase & Rubredoxina \\
\hline $\begin{array}{l}\text { Proteínas ligantes } \\
\text { de cálcio }\end{array}$ & Subtilisina & $\begin{array}{l}\text { Protease ácida } \\
(\mathrm{S}-\mathrm{S})^{\mathbf{c}}\end{array}$ \\
\hline Hemoglobinas & Papaína $(S-S)^{\mathbf{c}}$ & \\
\hline $\begin{array}{l}\text { Cro proteínas } \\
\text { repressoras }^{\mathbf{d}}\end{array}$ & Termolisina $(\mathrm{Ca})$ & \\
\hline
\end{tabular}

a Série de proteínas que forma canais através das membranas utilizando a movimentação das estruturas em hélice. Antagonistas e agonistas ligam-se a estas hélices para permeação de membranas. b S - C ligação cruzada enxofre-carbono. ${ }^{\text {c }} \mathrm{S}-\mathrm{S}$ ligação cruzada enxofre - enxofre. ${ }^{\mathrm{d}}$ Cro refere-se a um repressor em particular.

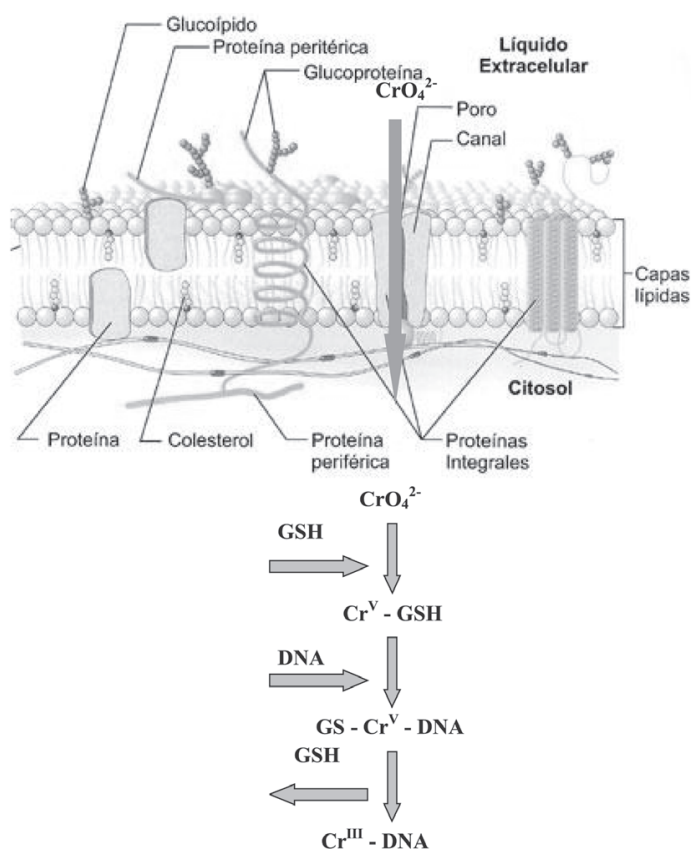

Figura 2. Modelo para captação celular do íon cromato $\mathrm{CrO}_{4}^{2-}$

um peptídeo intracelular. Nesta reação com GSH o ânion cromato é reduzido a $\mathrm{Cr}(\mathrm{V})$ e $\mathrm{Cr}(\mathrm{IV})$, e forma-se uma ligação $\mathrm{Cr}-\mathrm{S}$ com o grupo sulfidril do resíduo de cisteína da GSH. O íon metálico é então difundido para dentro do plasma, onde se liga ao DNA e sofre uma redução para $\mathrm{Cr}(\mathrm{III})^{23}$.

Para complexos metálicos ou metais neutros, a captação celular pode ocorrer por difusão passiva através da membrana celular. Este é o mecanismo que aparentemente opera a administração da cisplatina, com atividade anti-tumoral. A cisplatina é administrada por injeção intravenosa em solução salina aquosa. Aproximadamente metade da platina se liga às proteínas do soro e é excretada. $\mathrm{O}$ restante é distribuído para os vários tecidos ${ }^{24}$.

Íons metálicos são captados e absorvidos por células animais e vegetais, onde vão desempenhar dois papéis principais: atuam como cofatores enzimáticos, mas, também podem catalisar reações citotóxicas $^{25}$. 


\section{TOXIDEZ E HOMEOSTASE METÁLICA}

Os efeitos tóxicos causados por metais são geralmente resultado da ligação destes com bionucleofílos. Estes incluem aminoácidos, polipeptídios, proteínas e enzimas. Por exemplo, muitos metais pesados ligam-se a grupos tióis, os quais freqüientemente constituem os sítios ativos de muitas enzimas, cruciais para fornecimento de energia ou transporte de oxigênio nas células ${ }^{26}$. Evidências indicam que metais de transição atuam como catalisadores na deterioração oxidativa de macromoléculas biológicas e, portanto, a toxidez associada a estes metais deve-se, em parte, também aos danos oxidativos causados aos tecidos ${ }^{27}$.

Metais são os componentes fundamentais dos minerais da crosta terrestre. Por isso, encontram-se entre os mais antigos agentes químicos tóxicos de origem natural conhecidos pelo homem. O homem começou seu processamento e extração há 5000 anos atrás, mas somente no século XVIII, com o despontar do combustível fóssil, a manufaturação de metais começou a progredir.

Mineração, purificação, manuseio e processamento de metais conduziram à dispersão destes no meio ambiente em geral e, desta forma, danos à saúde da população pela ingestão de comidas e bebidas contendo ou contaminadas por metais ${ }^{28,29}$.

As principais intoxicações crônicas resultantes da exposição profissional (atividades mineradoras) estão associadas ao mercúrio e ao chumbo. Por outro lado, arsênio tem sido o metal mais empregado com fins suicidas e homicidas. As fontes de exposição têm ampliando muito com o desenvolvimento das atividades agrícolas e industriais. Um exemplo é o aumento do chumbo na atmosfera, que tem conduzido à contaminação até mesmo das zonas polares, relacionado com seu emprego como aditivo na gasolina.

Atualmente um grande número de atividades industriais implica na manipulação de metais. Entre elas destacam-se as indústrias de transformação, fundição e metalurgia em geral. Atividades específicas produzem riscos maiores frente a determinados elementos, como a exposição ao chumbo em fábricas de baterias e a exposição ao mercúrio em operações de eletrólise. Algumas das epidemias tóxicas alimentares mais graves, como o caso do $\mathrm{Hg}$ na enfermidade de Minamata, são produzidas por fungicidas usados no tratamento das colheitas de grãos. A fonte de exposição alimentar mantém sua importância quando se recorda a epidemia de arsenicosis por consumo de água de poço com alta concentração de As, em diversos países asiáticos ao longo dos anos $90^{30}$.

$\mathrm{O}$ uso de metais como agentes terapêuticos contribuiu para aumentar o interesse na compreensão da função de metais em processos biológicos ${ }^{31-33}$.

Existem metais cuja função em humanos já está bem estabelecida, tais como berílio, cuja intoxicação causa pneumonia, pois este metal consegue ser captado pelas células epiteliais ou, ainda, atravessar o revestimento epitelial pulmonar interagindo diretamente com fibroblastos e macrófagos intersticiais iniciando, assim, uma amplificação e conseqüente extensão da reação local. E ainda, osteosarcoma em animais e tumores na coluna em humanos. Índio usado na indústria eletrônica está entre os mais potentes metais teratogênicos já estudados. Em adição, a atividade anti-tumoral de selênio e molibdênio está diretamente relacionada com sua atuação antioxidante, atuando na proteção dos resíduos cisteína (reduzida) da glutationa (GSH, considerado o mais importante composto na destoxicação de carcinogênicos). Para a síntese do GSH é imprescindível o aporte à célula de cisteína, a qual constitui a principal fonte celular de grupos sulfidrílicos ${ }^{30,33}$.

\section{Aspectos toxicocinéticos}

As características e a efetividade do transporte através da membrana celular condicionam a expressão da toxidez das substâncias químicas ao determinar seu tempo de permanência no interior celular. Estas características dependem de diversos fatores, entre os quais se destacam a hidrossolubilidade e a lipossolubilidade, volatilidade, peso molecular e a existência de mecanismos específicos de transporte.

No caso dos compostos metálicos, as características mencionadas podem diferir muito entre compostos distintos de um mesmo elemento. As moléculas inorgânicas tendem a ser mais hidrossolúveis que as orgânicas, exceto alguns sais, como por exemplo os de chumbo que são totalmente insolúveis como sulfato, carbonato, cromato e fosfato.

Em relação à absorção e distribuição, os compostos organometálicos beneficiam-se de maior difusão porque são absorvidos por via digestiva e, inclusive, por via cutânea. A via respiratória é importante para o mercúrio, já que é o único metal volátil, entretanto, a não ser em quantidades muito altas, este metal não é absorvido pela via digestiva.

A exposição a humos e vapores metálicos, em condições extremas de temperatura, como o caso do $\mathrm{Pb}$ que é fagocitado pelos macrófagos alveolares, também é muito perigosa. Os sais de metais absorvem e difundem com maior dificuldade. O metabolismo dos compostos metálicos afeta, em geral, muito pouco a sua toxidez ${ }^{34}$.

A vida média dos compostos metálicos no organismo é variável porque tende a ser prolongada devido à sua afinidade protéica. Acumulam-se, por exemplo, $\mathrm{Pb}$ e $\mathrm{Cd}$, com vidas médias superiores há 20 anos; As e Cr não se acumulam e têm vidas médias de dias, podem ser detectados durante um tempo maior em lugares considerados como de eliminação, como as unhas ${ }^{26}$.

\section{Ação tóxica}

A toxidez dos compostos metálicos diferencia-se da maioria das moléculas porque depende muito das características do elemento metálico em questão. A expressão desta toxidez depende também das modificações toxicocinéticas derivadas do tipo de molécula: por exemplo, o mercúrio é principalmente agente neurotóxico por sua capacidade de atravessar a barreira hematoencefálica promovendo migração neuronal anormal; por outro lado, cloreto de mercúrio é nefrotóxico e consegue ser eliminado pelos rins.

Os alvos da toxidez metálica são geralmente as proteínas, muitas delas com atividade enzimática, afetando diversos processos bioquímicos, membranas celulares e organelas ${ }^{35,36}$.

Os metais também podem afetar a biodisponibilidade de outros metais. Isto ocorre quando um elemento se assemelha a outro na estrutura eletrônica, que tende então a exercer uma ação antagonista. Fato que pode ser exemplificado com a proteção do selênio frente aos efeitos tóxicos de concentrações excessivas de zinco e a ação de tungstênio frente à captação em excesso de selênio ${ }^{30}$. Fatores genéticos também influenciam na toxidez metálica. Existem certas síndromes de deficiência de íons metálicos que são inerentes a defeitos genéticos, por exemplo, deficiência de cobre gerando a doença de Menkes $^{37}$.

\section{Intoxicações metálicas}

Metais, como qualquer outro agente químico, podem produzir patologias agudas, desenvolvidas rapidamente pelo contato com uma única dose alta, ou crônica por exposição a doses baixas em longo prazo.

A toxidez aguda é pouco freqüente. São muito escassas as intoxicações suicidas ou homicidas por via digestiva, capazes de produzir quadros clínicos graves e fulminantes com comprometimen- 
to digestivo, cardiovascular e neurológico. A situação clínica mais freqüente é o quadro de febre dos metais, derivado da exposição respiratória no ambiente de trabalho a vapores metálicos ${ }^{37}$.

As intoxicações subagudas e crônicas, predominantemente de origem o ambiente de trabalho, têm diminuído com o controle das empresas dos valores limites a riscos ambientais por agentes químicos. As exposições a doses baixas em longo prazo, procedentes de fontes alimentares ou ambientais, podem produzir quadros típicos de intoxicação crônica. Outro possível efeito a longo prazo é a carcinogênese. A Agência Internacional de Pesquisa em Câncer (AIPC) incluiu no grupo I (agentes carcinógenos em humanos) o arsênio, o berílio, o cádmio, o cromo(VI) e o níquel ${ }^{27}$.

Por outro lado, deve-se recordar que a maioria dos oligoelementos considerados imprescindíveis para o funcionamento correto dos organismos em concentrações traço são metálicos: $\mathrm{Fe}, \mathrm{Cu}$, $\mathrm{Mn}, \mathrm{Zn}, \mathrm{Co}, \mathrm{Mb}, \mathrm{Se}, \mathrm{Cr}, \mathrm{Sn}$, Va, Si e Ni. Alguns alcalinos, Na, K, e alcalinos terrosos, tais como $\mathrm{Ca}$ e $\mathrm{Mg}$, são cátions de extraordinária importância para o funcionamento celular, onde se encontram em altas concentrações.

A ausência dos metais impede os organismos de completarem seu ciclo de vida na sua ausência porque estão diretamente envolvidos em seus processos biológicos. Suas concentrações ideais para manutenção da vida nestes organismos podem variar de miligramas $(\mu \mathrm{g})$ a gramas $(\mathrm{g})^{38}$, conforme a Tabela 2.

Tabela 2. Valores médios das concentrações dos metais presentes na composição do corpo humano (referência: homem adulto de $70 \mathrm{~kg}$ )

\begin{tabular}{lcc}
\hline Metais & $\begin{array}{c}\text { Corpo } \\
(\mathrm{massa}-\mathrm{g})\end{array}$ & $\begin{array}{c}\text { Cérebro } \\
(\text { massa }-\mu \mathrm{g})\end{array}$ \\
\hline Cálcio & 1050 & \\
Potássio & 140 & \\
Sódio & 105 & \\
Magnésio & 35 & \\
Ferro & 4,2 & \\
Zinco & 2,3 & \\
Rubídio & 1,1 & \\
Zircônio & 0,3 & \\
Estrôncio & 0,14 & \\
Cobre & 0,11 & \\
Alumínio & 0,10 & \\
Chumbo & 0,08 & \\
Antimônio & 0,07 & \\
Cádmio & 0,03 & \\
Estanho & 0,03 & \\
Manganês & 0,02 & \\
Vanádio & 0,02 & \\
Bário & 0,02 & \\
Arsênio & 0,01 & \\
Níquel & 0,01 & \\
Cromo & 0,005 & \\
Cobalto & 0,003 & \\
Molibdênio & $<0,005$ & \\
Lítio & 0,002 & \\
\hline
\end{tabular}

Pode-se verificar que a homeostase metálica é tênue (Figura 3) tanto na deficiência quanto no excesso de íons metálicos, constituindo doenças já bem caracterizadas, em animais e vegetais, conforme apresentado de forma resumida na Tabela 3.

A homeostase é um tipo de tamponamento. Um tampão químico depende do seguinte equilíbrio:

$\mathrm{M}+\mathrm{L} \longleftrightarrow \mathrm{ML}$ mudanças na concentração de $\mathrm{M}$ total não refletem diretamente no M livre e na presença de L. A efetividade do tamponamento depende da quantidade de L e da constante de ligação. A homeostase também está restrita a considerações cinéticas: a velocidade em que o metal é liberado ou precipitado no meio intracelular constitui um gradiente de energia que deve ser considerado.

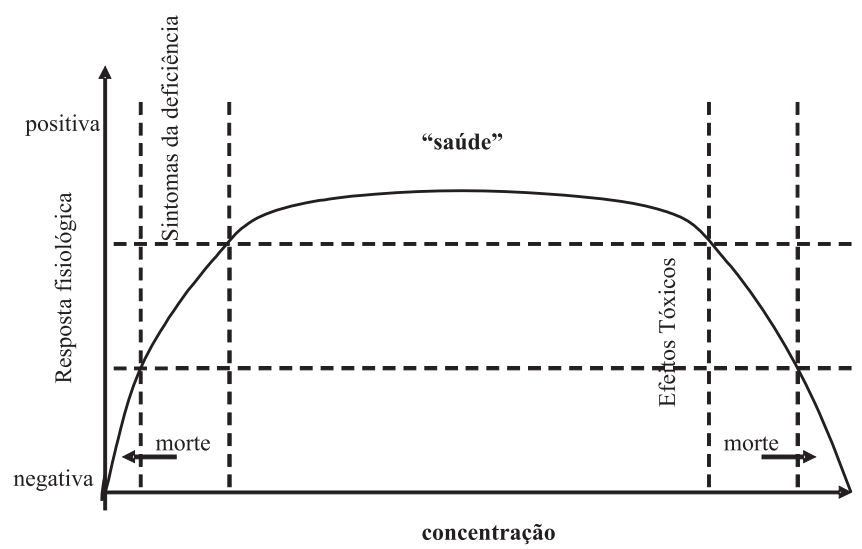

Figura 3. Diagrama da resposta fisiológica a alterações na homeostase metálica

\section{QUELATOTERAPIA}

A intoxicação por elementos metálicos beneficia-se de um tipo de tratamento específico baseado em sua reatividade química, através de sua capacidade de formação de complexos com diversas substâncias denominadas agentes quelantes. Formam-se compostos de coordenação atóxicos e hidrossolúveis, que são eliminados pela urina. Por outro lado, as patologias oriundas da carência de íons metálicos nos organismos são geralmente tratadas com suplementação alimentar e dieta adequada ${ }^{42}$.

A quelação refere-se à coordenação de dois ou mais átomos de um ligante ao átomo metálico central. O complexo metal-quelato resultante apresenta uma estabilidade não usual aos compostos de coordenação devido, em parte, a fatores entrópicos que acompanham a liberação de ligantes não quelantes da esfera de coordenação, conforme exemplificado na Equação 6 para a quelação do níquel (II) em solução aquosa pelo ligante hexadentado etilenodiaminotetraacetato (1).

$\left[\mathrm{Ni}\left(\mathrm{OH}_{2}\right)_{6}\right]^{2+}+\mathrm{H}_{2} \mathrm{EDTA}^{2-} \longrightarrow[\mathrm{Ni}(\mathrm{EDTA})]^{2-}+4 \mathrm{H}_{2} \mathrm{O}+2 \mathrm{H}_{3} \mathrm{O}^{+}$

Ligantes deste tipo são utilizados em medicina para o tratamento da toxidez de íons metálicos derivada do excesso enquanto aditivos alimentares e para limitar sua disponibilidade a bactérias patogênicas e impedir seus ciclos de vida.

Um importante exemplo do efeito quelato em Química Bioinorgânica Medicinal é aquele representado pela porfirina. Estas moléculas macrocíclicas têm quatro anéis pirróis coplanares vizinhos com átomos de nitrogênio direcionados ao redor do centro metálico. O resultado do quelato metal-porfirina é um complexo termodinamicamente muito estável, capaz de acomodar uma variedade de íons metálicos em diferentes estados de oxidação. Como consequiência, este quelante fornece grupos bioinorgânicos funcionais com ampla ocorrência e utilidade em medicina, sendo encontrados nos citocromos $(\mathrm{Fe})$, clorofilas $(\mathrm{Mg})$ e vitamina B-12 (Co), entre outros muitos exemplos.

Os agentes quelantes devem ser hidrossolúveis, capazes de penetrar nos tecidos e alcançar os metais através de afinidade química. 
Tabela 3. Sintomas e patogenias relacionadas com o desequilíbrio na homeostase metálica ${ }^{39-41}$

\begin{tabular}{|c|c|c|}
\hline Metal & Deficiência & Excesso ou envenenamento \\
\hline Cálcio & $\begin{array}{l}\text { Tétano; decréscimo da densidade óssea em } \\
\text { recém-nascidos; defeitos de calcificação } \\
\text { de ossos e dentes; osteoporose }\end{array}$ & $\begin{array}{l}\text { Comprometimento respiratório e perda da função do músculo } \\
\text { cardíaco; síndrome do leite-alcalino }\end{array}$ \\
\hline Magnésio & $\begin{array}{l}\text { Hypomagnesemia; disfunções neuromusculares } \\
\text { (tremores e convulsões); cirrose hepática, } \\
\text { deficiências diuréticas e defeitos de absorção } \\
\text { de nutrientes }\end{array}$ & $\begin{array}{l}\text { Enfraquecimento muscular; coma; síndrome da } \\
\text { água dura - diálise }\end{array}$ \\
\hline Cromo & $\begin{array}{l}\text { Comprometimento da tolerância à glicose; } \\
\text { risco de doenças cardiovasculares }\end{array}$ & Comprometimentos renais; dermatites; sintomas gastrintestinais \\
\hline Cobalto & Anemia perniciosa & Cardiomiopatia; policitemia \\
\hline Cobre & Síndrome de Menkes: desordens sanguíneas & Doença de Wilson: depósito de cobre no fígado, cérebro e rim \\
\hline Zinco & $\begin{array}{l}\text { Acrodermatite enteropática; atrofia } \\
\text { hipogonadal; problemas respiratórios }\end{array}$ & Desordens pulmonares \\
\hline Molibdênio & Carcinogenesi nos seios; câncer no esôfago & Enfraquecimento dos ossos; despigmentação; anemia em gado \\
\hline Estanho & Retardo do crescimento* & Sintomas gastrintestinais; distúrbios neuromusculares \\
\hline Vanádio & Retardo do crescimento* & $\begin{array}{l}\text { Depressão ou mama em humanos; anemia em animais e } \\
\text { danos ao fígado, rim e coração }\end{array}$ \\
\hline Níquel & $\begin{array}{l}\text { Retardo do crescimento ósseo*; } \\
\text { anormalidades nos hepatócitos* }\end{array}$ & $\begin{array}{l}\text { Neurotoxicidade; pneumonite; hipoglicemia; desordens } \\
\text { gastrintestinais; dermatite crônica; carcinogenese respiratória }\end{array}$ \\
\hline Manganês & Retardo do crescimento* & $\begin{array}{l}\text { Disfunções no fígado; distúrbios neuromusculares; sintomas } \\
\text { similares ao Parkinsonismo }\end{array}$ \\
\hline Sódio & $\begin{array}{l}\text { Hiponatremia; síndrome da secreção } \\
\text { inapropriada de hormônio antidiurético }\end{array}$ & Hipernatremia \\
\hline Potássio & Bulimia; anorexia nervosa; acidez renal & Comprometimento das funções diuréticas \\
\hline
\end{tabular}

* animais

Entre os mais utilizados em medicina estão $0^{43}$ : dimercaprol - utilizado nas intoxicações por arsênio, chumbo e mercúrio ${ }^{44}$; ácido 2,3dimercapto-1-propanossulfônico (DMPS) e ácido meso-2,3dimercatossuccínico - derivados de dimercaprol, hidrossolúveis empregados na intoxicação crônica pelos mesmos agentes ${ }^{45}$; derivados do ácido etilenodiaminotetraacético (EDTA) tais como cicloexano1,2-diaminotetraacético(CDTA), trietilenotetraminoexaacético (TTHA) - utilizados na remoção de chumbo, estrôncio radioativo, cobalto, manganês e principalmente cálcio ${ }^{46}$; dietilenotriaminopentaacético (DTPA) - também derivado do EDTA empregado na remoção de isótopos de plutônio e como regulador da absorção de cobre; penicilamina ( $\beta, \beta$ - dimetilcisteína)- empregada (por via oral) para remoção de $\mathrm{Cu}$ (doença de Wilson), mercúrio e chumbo ${ }^{47}$; desferrioxiamina - B $\left(\right.$ Desferral $\left.^{\circledR}\right)$ - utilizada para remoção de ferro ${ }^{48}$.

A quelatoterapia tem sido a base da terapêutica contra o excesso de metais nas últimas quatro décadas. Agentes quelantes são usados clinicamente como antídotos para intoxicação metálica aguda e crônica. Estes compostos se ligam e aumentam a velocidade de excreção dos elementos tóxicos. Infelizmente nos últimos anos, pequenas atividades embriotóxicas e teratogênicas de alguns agentes quelantes têm sido relatadas em mamíferos ${ }^{49-51}$. Linhas de pesquisa que visam desenvolver novos agentes quelantes têm se estabelecido no mundo inteiro ${ }^{25,48,50,52-63}$.

\section{CONCLUSÕES}

Esforços para elucidar o mecanismo de coordenação que envolve a participação de íons metálicos com funções específicas em sistemas biológicos têm impulsionado o crescimento da Química Bioinorgânica Medicinal nos séculos XX e XXI. A principal proposta deste artigo foi correlacionar, brevemente, função, estrutura e reatividade de elementos inorgânicos nos organismos vivos elucidados até agora.
Pode-se concluir que complexos metálicos expressivos para manutenção da saúde podem ser de origem endógena (tais como metaloproteínas) e exógena. Complexos metálicos exógenos são expressivamente representados pelos fármacos ou inconvenientemente (de forma descontrolada) por poluentes do ar e da dieta. A atividade farmacológica de um complexo metálico depende do metal, da biomolécula ou de ambos. Dois fatores são importantes no planejamento de complexos metálicos para aplicação em medicina: estabilidade termodinâmica e seletividade.

Finalmente, o sucesso do uso de complexos metálicos como agentes terapêuticos depende do controle de suas propriedades cinéticas e termodinâmicas por meio da escolha adequada do estado de oxidação, tipo e número de biomoléculas ligantes, e geometria de coordenação. Este mecanismo torna possível encontrar atividade e especificidade biológica e, muito mais importante, minimizar os efeitos colaterais.

\section{AGRADECIMENTOS}

Aos Profs. C. A. M. Fraga e C. M. Sant'Anna pela colaboração. À FAPERJ, CNPq, CAPES, FUJB, Fundação José Pelúcio Ferreira, Pronex pelo apoio financeiro.

\section{REFERÊNCIAS}

1. Castillo-Blum, S. E.; Barba-Behrens, N.; Coord. Chem. Rev. 2000, 196, 3.

2. Lippard, S. J.; Nat. Chem. Biol. 2006, 2, 10.

3. van Eldik, R.; Coord. Chem. Rev. 2007, 13, 1649.

4. van Eldik, R.; Coord. Chem. Rev. 1999, 182, 373.

5. van Eldik, R.; Chem. Rev. 2005, 105, 6.

6. Williams, R. J. P.; Coord. Chem. Rev. 1990, 100, 573.

7. Comba, P.; Coord. Chem. Rev. 1999, 185, 81.

8. Berners-Price, S. J.; Sadler, P. J.; Coord. Chem. Rev. 1996, 151, 1.

9. Comba, P.; Sickmüller, A. F.; Inorg. Chem. 1997, 36, 4500. 
10. Comba, P.; Jakob, H.; Helv. Chim. Acta 1997, 80, 1983.

11. Lever, A. B. P.; Inorg. Chem. 1991, 30, 1980.

12. Hambley, T. W.; Inorg. Chem. 1998, 27, 2496.

13. Ventur, D.; Wieghardt, K.; Nuber, B.; Weiss, J.; Z. Anorg. Allg. Chem. 1987, $551,33$.

14. Comba, P.; Coord. Chem. Rev. 1998, 182, 343.

15. Bramley, R.; Broson, M.; Sargeson, A. M.; Schäffer, C. E.; Inorg. Chem 1987, 26, 814.

16. Rulisek, L.; Vondrásek, J.; J. Inorg. Biochem. 1998, 71, 115.

17. Pearson, R. G.; J. Am. Chem. Soc. 1963, 85, 3533.

18. Albrecht-Gary, A. M.; Crumbliss, A. L.; Met. Ions Biol. Syst. 1998, 35, 239.

19. Avery, S. V.; Tobin, J. M.; Appl. Environ. Microbiol. 1993, 59, 2851.

20. Donia, A. M.; Thermochim. Acta 1998, 320, 187.

21. Finney, L. A.; O'Halloran, T. V.; Science 2003, 300, 931.

22. Iqbal, K. S.; Cragg, P. J.; Dalton Trans. 2007, 7, 1.

23. Hostynek, J. J.; Food Chem. Toxicol. 2003, 41, 327.

24. Carunchio, V.; Polyhedron 2002, 21, 1313.

25. Carcelli, M.; Mazza, P.; Pelizzi, C.; Zani, F.; J. Inorg. Biochem. 1995, 57, 43.

26. Starkey, B. J.; Ann. Clin. Biochem. 1998, 24, 337.

27. Stohs, S. J.; Bagchi, D.; Free Radical Biol. Med. 1995, 2, 321.

28. Apostoli, P.; J. Chromatogr. 2002, 778, 63.

29. Yung, C. Y.; Pharmacol., Biochem. Behav. 1894, 21, 41.

30. Janssen, C. R.; De Schamphelaere, K.; Heijerick, D.; Muyssen, B.; Lock K.; Bossuyt, B.; Vangheluwe, M.; van Sprang, P.; Hum. Ecol. Risk Assess. 2000, 6, 1003.

31. Cohen, S. M.; Curr. Opin. Chem. Biol. 2007, 11, 2.

32. Sharma, V.; Mini-Rev. Med. Chem. 2005, 5, 4

33. Crammer, J. L.; Br. J. Psychiatry 1983, 143, 85

34. Chan, K.; Chemosphere 2003, 52, 1361.

35. Mercer, J. F. B.; Trends Mol. Med. 2001, 7, 64.

36. Theil, E. C.; Thorp, H. H.; Curr. Opin. Chem. Biol. 2005, 9, 95.

37. Sayre, L. M.; Perry, G.; Smith, M. A.; Curr. Opin. Chem. Biol. 1999, 3 , 220.

38. Kaim, W.; Schwederski, B.; Bioinorganic Chemistry: Inorganic Elements in the Chemistry of Life, John Wiley \& Sons: New York, 1994, p. 15.
39. Kapaki, E.; Zournas, C.; Kanias, G. Sambelis, T.; Kakanmi, A.; Papageorgiou, C.; J. Neurol. Sci. 1997, 147, 171.7.

40. Ernest, E.; Coon, J. T.; Clin. Pharmacol. Ther. 2001, 70, 497

41. Reedijk, J.; Curr. Opin. Chem. Biol. 1999, 3, 236.

42. Benite, A. M. C.; Machado, B. C.; Machado, S. P.; Quim. Nova. 2002, 25, 1155 .

43. Aaseth, J.; Hum. Toxicol. 1983, 257.

44. Kurland, L. T.; Faro, S. N.; Siedler, H.; Neurology 1960, 1, 370

45. Kosmider, S.; Petelenz, T.; Pol. Arch. Med. Wewn 1962, 32, 437.

46. Audesirk, G.; Neurotoxicology 1993, 14, 137.

47. Markovac, J.; Goldstein, G. W.; Nature 1988, 334, 71.

48. Farkas, E.; Ėnyedy, E. A.; Csóka, H.; Polyhedron 1999, 18, 1391.

49. Domingo, J. L.; Reprod. Toxicol. 1995, 9, 105.

50. Richardson, D. R.; Antimicrob. Agents Chemother. 1997, 41, 2061.

51. Ferrer, A.; Anales Sis San Navarra 2003, 26, 141.

52. Giorgi, G.; Savini, L.; Chiasserini, L.; Nencini, C.; Pellerano, C.; Polyhedron 1998, 17, 3851.

53. Mabeza, G. F.; Loyevsky, M.; Gordeuk, V. R.; Weiss, G.; Pharmacol. Ther. 1999, 81, 53.

54. Walcourt, A.; Loyevsky, M.; Lovejoy, D. B.; Gordeuk, V. R.; Richardson, D. R.; Int. J. Biochem. Cell Biol. 2004, 36, 401.

55. van Reyk, D.; Sarel, S.; Hunt, N.; Biochem. Pharmacol. 2000, 60, 581.

56. Gokhale, N. H.; Padhye, S. B.; Croft, S. M.; Kendrick, H. D.; Davies, W.; Anson; C. E.; Powell, A.K.; J. Inorg. Biochem. 2003, 95, 249.

57. Dongli, C.; Handong, J.; Hongyun, Z.; Deji, C.; Jina, Y.; Jian, L. B.; Polyhedron 1994, 13, 57 .

58. Barreiro, E. J.; Fraga, C. A. M.; Miranda, A. L. P.; Rodrigues, C. R.; Quim. Nova 2002, 25, 129

59. Bacchi, A.; Carcelli, M.; Pelagatti, P.; Pelizzi, C.; Pelizzi, G.; Zani, F.; J. Inorg. Biochem. 1999, 75, 123

60. Sluis-Cremer, N.; Arion, D.; Parniak, M. A.; Mol. Pharmacol. 2002, 62, 398.

61. Rodriguez-Argüeles, M. C.; Ferrari, M. B.; Bisceglie, F.; Pelizzi, C.; Pelosi, G.; Pinelli, S.; Sassi, M.; J. Inorg. Biochem. 2004, 98, 313.

62. Lanthier, C. M.; Parniak, M. A.; Dmitrienko, G. I.; Bioorg. Med. Chem. Lett. 1997, 12,1557.

63. Arion, D.; Sluis-Cremer, N.; Min, K. L.; Abram, E.; Fletcher, R. S.; Parniak, M. A.; J. Biol. Chem. 2002, 11,1370. 